\title{
Contribution of the Sensitivity Analysis in Groundwater Vulnerability Assessing Using the DRASTIC Method: Application to Groundwater in Dabou Region (Southern of Côte d'Ivoire)
}

\author{
Jacques Édoukou Djémin*, Jean Kan Kouamé, Kouakou Serge Deh, Amani Tawa Abinan, \\ Jean Patrice Jourda
}

Department of Sciences and Water Technology and Environment Engineering (Laboratory of Remote Sensing and Spatial Analysis Applied to Hydrogeology), Félix Houphouët-Boigny University, Abidjan, Côte d'Ivoire Email: *djedoukouj@yahoo.fr

Received 4 December 2015; accepted 25 January 2016; published 28 January 2016

Copyright (C) 2016 by authors and Scientific Research Publishing Inc.

This work is licensed under the Creative Commons Attribution International License (CC BY). http://creativecommons.org/licenses/by/4.0/

\section{(c) (i) Open Access}

\begin{abstract}
The groundwater constitutes the main source of drinking water for the populations in the Dabou region which is marked by a multiplication of socio-economic activities. The quality of groundwater is increasingly tested by diverse sources of pollution caused by these human activities. In order to preserve their quality against any form of contamination, the present study aims to assess the groundwater vulnerability in this region and to highlight the relative importance of hydrogeological parameters which will be taken into account in this assessment. The assessment of the intrinsic vulnerability is to identify the most sensitive zones in order to prevent the groundwater pollution risks on the surface of the ground. To do it, the DRASTIC method is applied through a GIS. The GIS has also used to perform sensitivity analysis through the map removal and the singleparameter sensitivity analysis tests. The indexes calculated for the DRASTIC vulnerability map vary from 95 to 187 of the North towards the South. This vulnerability map presents four classes: very high $(26.22 \%)$ in the South and the East, high $(37.71 \%)$ in the Center, the North-East and the North-West, moderate $(34.73 \%)$ to the North and the West and low $(1.34 \%)$ in the North. The DRASTIC vulnerability map is heavily influenced by the impact of vadose zone and the depth to water table according to the first test. For the second test, it is the impact of vadose zone, the aquifer media and the soil media which have a more significant impact on the vulnerability map. Both sensitivity analysis tests confirm that the impact of vadose zone therefore sediment type is more implied in this assessment of the groundwater vulnerability in the Dabou region.
\end{abstract}

${ }^{*}$ Corresponding author.

How to cite this paper: Djémin, J.É., et al. (2016) Contribution of the Sensitivity Analysis in Groundwater Vulnerability Assessing Using the DRASTIC Method: Application to Groundwater in Dabou Region (Southern of Côte d'Ivoire). Journal of Environmental Protection, 7, 129-143. http://dx.doi.org/10.4236/jep.2016.71012 
Keywords

Pollution, Groundwater Vulnerability, DRASTIC, Sensitivity Analysis

\section{Introduction}

The groundwater is the main source of drinking water for some populations. The estimates indicate that nearly two billion people in the world depend directly on the groundwater [1]. Groundwater used not only for human consumption but also the development of socio-economic activities. However, they are exposed to many sources of diffuse and punctual pollution resulting from human activities, particularly the agricultural practices [2]. The progress and the generalization of industrialization have also increased the risk of groundwater pollution by using of hazardous substances [3]. The introduction of pollutants into water tables deteriorates the quality of groundwater and reduces their consumable nature [4]. Given this situation, it is necessary to study the aquifers vulnerability, which is defined as the set of natural geological and hydrogeological characteristics that determine susceptibility of groundwater to contamination by human activities [5]. The vulnerability assessment therefore aims to prevent potential risks of pollution by the delimitation of sensitive areas in order to control the activities at the ground surface to protect the groundwater quality. The groundwater of the study area is exploited in both urban and rural areas to satisfy the water requirements of the populations. However, in some cases, nitrate concentrations of exploited water can reach $51.7 \mathrm{mg} \cdot \mathrm{L}^{-1}$ [6]. This high concentration of nitrates in collected water can be related to several factors such as the intensive use of agricultural inputs and pesticides in agro-industrial plantations for the improvement of the productions. Moreover, the uncontrolled urbanization favoring the installation of inadequate systems of cleansing and the insufficiency of these systems for a better management of the domestic and industrial waste water rejections can be the causes of a real deterioration of these waters quality. Added to this is the storage of household waste promoting the production of leachate (lixiviates) which can cause the groundwater contamination in this region. Indeed, to limit and prevent contamination risks of these waters in order to preserve their quality, it is necessary to establish the vulnerability map which is under the influence of several hydrogeological parameters. This is firstly to assess the groundwater vulnerability from the DRASTIC method that uses seven hydrogeological parameters and secondly to assess the relative importance of each parameter based on sensitivity analysis tests. The sensitivity analysis will make it possible to apprehend the most determining parameters in the assessment of the intrinsic vulnerability in this region. Application of DRASTIC method and sensitivity analysis tests requires the use of a Geographic Information System (GIS) which is the gateway to the database and output decisional thematic maps.

\section{Presentation of Study Area}

The study area is the Dabou region which is a coastal area of southern Côte d'Ivoire (Figure 1). It is between longitudes $4^{\circ} 10^{\prime}$ and $5^{\circ} 00^{\prime}$ West and latitudes $5^{\circ} 00^{\prime}$ et $5^{\circ} 40^{\prime}$ North with an estimated area at $2435 \mathrm{~km}^{2}$. The population is estimated at 238,294 inhabitants according to the last population census [7]. The study area consists of three departments: Dabou which occupies much of the area, Jacqueville and Grand Lahou. The climate is equatorial transition characterized by four seasons with two dry seasons which alternates with two rainy seasons. The average rainfall ranges around $1400 \mathrm{~mm}$. The direct infiltration feeding the water tables is estimated on average at $382 \mathrm{~mm}$ a year which represents $26.30 \%$ of the rainfall. This coastal area is characterized by a hydrographic network with an average drainage density equal to $1.7 \mathrm{~km} . \mathrm{km}^{-2}$ dominated by Ira River and Ebrie Lagoon. The Agneby and Bandama rivers respectively to the East and West of the area are hydraulic limits of the basin.

Geological and hydrogeological, the study area belongs to the coastal sedimentary basin composed of postEburnean formations characterized by quaternary clayey sands and vases and Continental Terminal clayey sands [8]. This cretaceous to quaternary basin has enormous potential groundwater [9]. These groundwater resources are contained in aquifers three levels of unequal importance [10]. The aquifer system contains the quaternary water table and that of the continental terminal. The aquifer system is exploited by more than 217 boreholes (drillings) with an average speed of $18.79 \mathrm{~m}^{3} \cdot \mathrm{s}^{-1}$. 


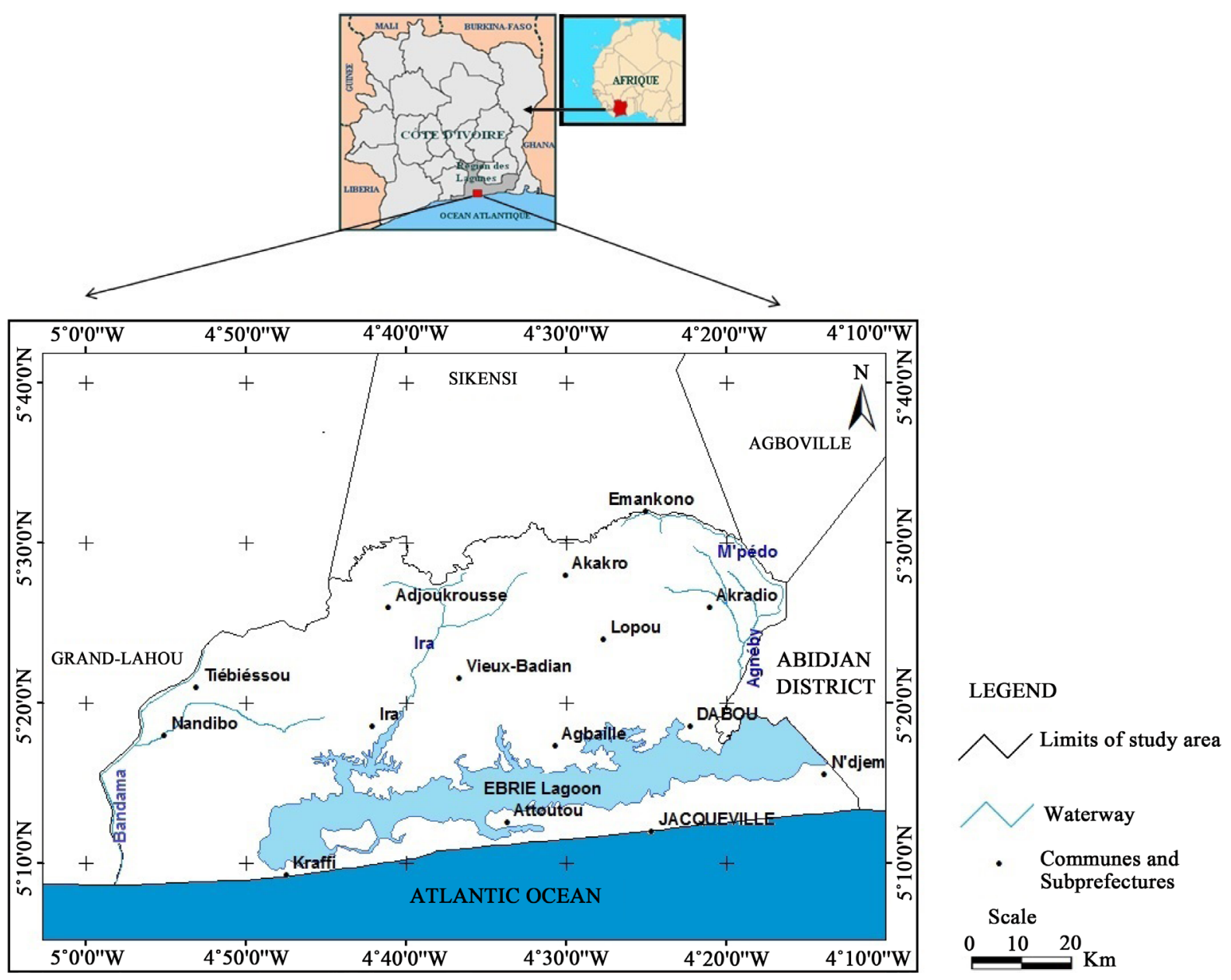

Figure 1. Location map of the study area.

\section{Materials and Method}

\subsection{Data Acquisition and Materials}

The drillings data used in this study were collected from the Water Resources Direction. The drillings data such as transmissivity which were used to estimate the hydraulic conductivity values starting from the thicknesses of calculated water table were collected in previous study. Identification of geological formations that make up the aquifer system in the study area required the drilling logs that exist in previous research of [6]. The geological map (scale: 1/200,000) provided by the Cartography and Remote sending Center has delineated the study area. The Digital Elevation Model (DEM) used in this study is a SRTM (Shuttle Radar Topography Mission) image. It was collected in 2008 by the American Spatial Shuttle "Endeavour" available from (http://strm.csi.cgiar.org) and was used to delineate the DEM of the study area which enabled subsequently estimating slopes of this zone.

The GIS software used in this study is ArcGIS 9.3 offered in three levels of licenses (ArcView, ArcEditor, and ArcInfo). The three modules used in this study are: ArcCatalog that enables the management of the database or the geodatabase; ArcMap used for geoprocessing and ArcScene used for overlaying the information planes. ArcGIS 9.3 has several ex-tensions are those used "Spatial Analyst or GRID and 3D Analyst". Excel software has allowed the entry of alphanumeric data that is imported into the ArcGIS environment through its module ArcCatalog.

\subsection{DRASTIC Method}

The DRASTIC method was developed by the services of the American Agency of Environmental Protection 
USEPA [11]. It estimates the potential for pollution and to assess the vertical groundwater vulnerability [12]. It takes into account most of the hydrogeological factors that affect and control the flow of groundwater [13]. It is a method to index weighting with seven parameters whose initials form the acronym DRASTIC: Depth to water table (D), net aquifer Recharge (R), Aquifer media (A), Soil media (S), Topography (T), Impact of vadose zone (I) and Finally the hydraulic Conductivity of the aquifer (C). The development of the intrinsic vulnerability map using the DRASTIC method can be summarized into four phases: (i) data acquisition; (ii) the preparation of the map database; (iii) calculating the vulnerability index and; (iv) the classification index according to DRASTIC classes to determine vulnerability map.

- Definition of the DRASTIC data

The seven DRASTIC parameters are defined as follows:

- The Depth to water table: represents the vertical distance traversed by a contaminant over ground to reach the water table (saturated zone of the aquifer). The larger this depth is, the higher the contaminant puts enough time to reach the water table. It corresponds to the static level in drillings.

- Net recharge is the main vehicle for the transport of contaminant. The larger this recharge is, the more the risk of contamination is high. The net recharge determined in the zone considered is of $382 \mathrm{~mm}$ a year.

- The Aquifer media identifies the size of the saturated ground. It is involved in trapping the pollutant that can escape the power of absorption or adsorption of the soil. The larger the particle size is finer, trapping the pollutant is great. This parameter was identified from fifteen drill logs made in previous study.

- The Soil media controls the downward movements of contaminants. Indeed, the presence of fine materials (clays, silts and silt) and organic matter in the soil reduces the intrinsic permeability and retards the migration of contaminants, by physico-chemical processes (adsorption, ion exchange, oxidation, biodegradation). For this parameter, geotechnical map has been used to identify soil types in the study area.

- The Topography or slope (\%) favors the runoff of surface waters at the expense of infiltration. The steeper the slope of the land, the more water runoff is important and therefore the groundwater contamination is low. The slope map is obtained by extraction of the contours of the DEM and transforming them into fashion TIN (Triangular Irregular Network) with the extension "3D Analyst” of GIS. The "Slope” of this extension allows converting the TIN in a slope map.

- The Impact of vadose zone is defined as the fraction between the water table and the surface where the pores are partially saturated with water. The permeability of the unsaturated zone controls the flow of pollutants and their arrival at the water table. Its impact is determined from the texture of the lands that constitute it. Percolation of the pollutant to the water table is so much greater that the texture is favorable. This parameter has been identified from the drill logs produced in the area.

- The hydraulic conductivity is the rate at which water flows through an aquifer. It refers to the ability of the geological formations of the aquifer to transmit water. More this setting, the greater the transfer of the pollutant is fast. The conductivity is determined by the ratio of the transmissivity and the estimated thickness of the water tables.

- Developing of the database maps

The map database is performed in the coordinate system of Universal Transverse Mercator (UTM), World Geodesic System (WGS) 84, Zone 30 and Northern Hemisphere. The geological map was georeferenced and used to scan the survey area using the functions “Georeferencing and Editor” of ArcInfo/ArcGIS 9.3. The method requires spatial interpolation or the DRASTIC parameters. Interpolation is the procedure for estimating the value of a variable in a particular place, from a number of measurement points to calculate each point in the study area [14]. In this study, the chosen interpolation method is the Inverse Distance Weighting (IDW) which is an estimate by linear combination of the values of the known points and is available in "Spatial Analyst" of ArcInfo/ArcGis 9.3".

- Distribution of water points

The study was conducted on 217 drillings which spatial distribution is shown in Figure 2. The values of DRASTIC parameters of each water point made it possible to carry out the interpolations by the chosen method for determining the thematic maps.

- Developing of the thematic maps

The database developed in the framework of this study has two components. A descriptive or alphanumeric component developed under Excel. These data were then imported into ArcInfo/ArcGIS through its ArcCatalog module intended to store and manage this numerical data. The raw values of each DRASTIC parameter were 


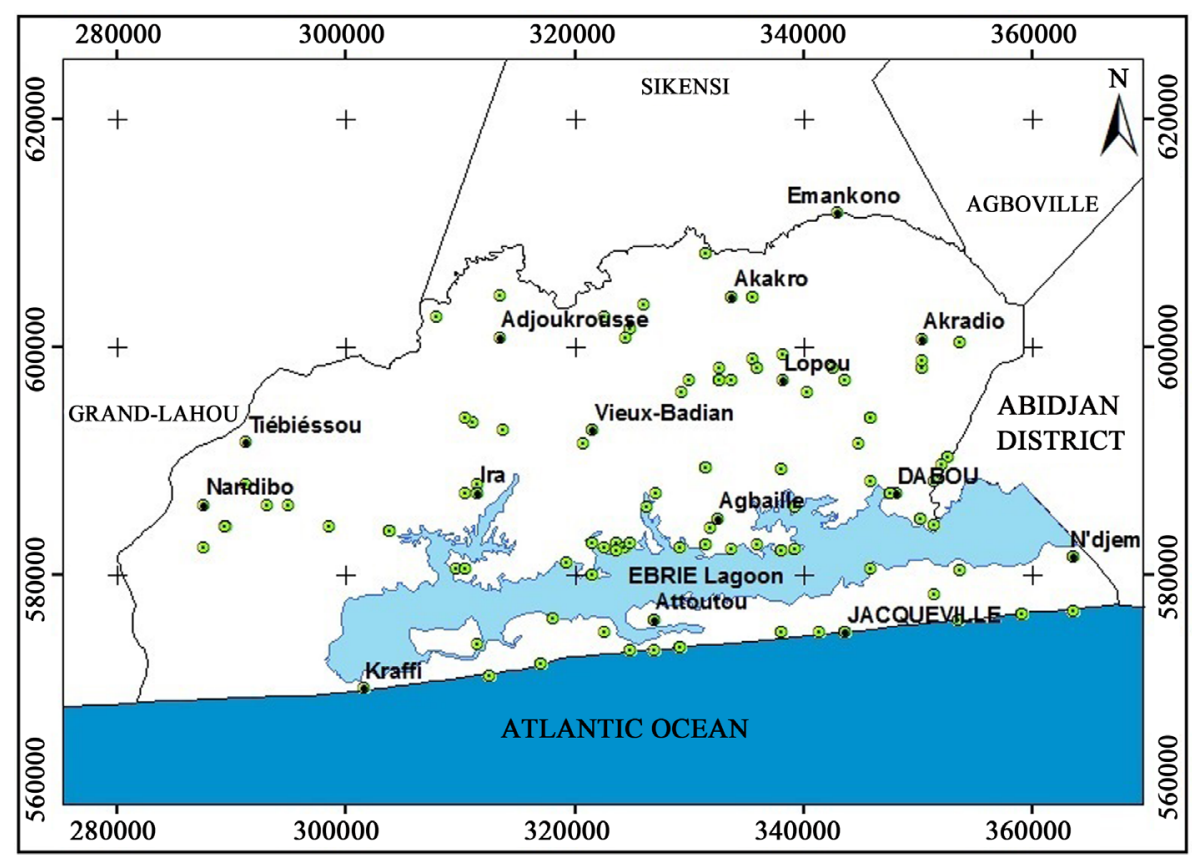

LEGEND

- Water points location (drillings)

Limits of study area

- Communes and Subprefectures

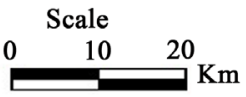

Figure 2. Water points distribution map in the study area.

transferred in ArcMap where the interpolations have been performed by setting the spatial resolution (pixel) at $250 \mathrm{~m} \times 250 \mathrm{~m}$. Thereafter, the classifications according to the method were performed (Table 1) with the function "Reclassify of Spatial Analyst" of the GIS.

Each class is assigned an index named as a symbol (c), typically from 1 to 10 depending on the degree of its impact on the pollution of the aquifer. A weighting factor (p) or fixed multiplication factor of 1 to 5 is assigned to each parameter according to the method in order to relativize their respective importance in terms of vulnerability. This factor reflects the influence degree of each of them in the vulnerability assessment and is imposed by the method. DRASTIC parameter maps are obtained after this manipulations series in the GIS.

Thematic maps of various parameters are established based on DRASTIC ratings. The areas characterized by low scores indicate the favorable hydrogeological conditions to natural groundwater protection. However, for high ratings, these conditions are more and more critical as the vulnerability is high and groundwater is likely to be reached by possible pollution coming from the soil surface.

- Calculation of the DRASTIC vulnerability index

After mapping the parameters according to the rating system of the DRASTIC method, they were weighted. The weighting was to multiply each thematic map (DRASTIC ratings map) by its respective weight. The superposition of different layers (thematic maps) on a result-layer will allow calculating DRASTIC index map. The superimposed layers must obviously have the same cartographic characteristics namely the same projection system, the same units of length, the same geographical extent and also the same resolution as all calculations will be made on the same matrix [15]. The final vulnerability index or noted DRASTIC Vulnerability Index is equal to the weighted sum of seven parameters. The DRASTIC Vulnerability Index (DVI) is calculated by the Equation (1) [11]:

$$
\mathrm{DVI}=D c \times D p+R c \times R p+A c \times A p+S c \times S p+T c \times T p+I c \times I p+C c \times C p
$$

With: $D, R, A, S, T, I, C$ are the parameters mentioned above;

$p$ is weighting factor given to each parameter;

$c$ is rating assigned to each parameter.

- Classification index based on DRASTIC classes

The possible range of values vulnerability index is found between 23 and 226 in the case of the standard version. The values obtained are grouped in eight classes which each one corresponds to a vulnerability degree [11]. The reclassification of the index map within the ranges defined by the method used to develop the groundwater vulnerability to pollution map. 
Table 1. Standardization of the parameters using the DRASTIC method [11] (modified).

\begin{tabular}{|c|c|c|c|c|c|}
\hline \multicolumn{3}{|c|}{ DEPTH TO WATER TABLE (meter) } & \multicolumn{3}{|l|}{ TOPOGRAPHY (slope \%) } \\
\hline Range (meter) & Rating & Weight & Range (\%) & Rating & Weight \\
\hline 0 - 1.5 & 10 & & 0 - 2 & 10 & \\
\hline $1.5-4.5$ & 9 & & $3-6$ & 9 & \\
\hline $4.5-9$ & 7 & & $7-12$ & 5 & 1 \\
\hline $9-15$ & 5 & 5 & $13-18$ & 3 & \\
\hline $15-23$ & 3 & & $>18$ & 1 & \\
\hline $23-30$ & 2 & & IMPACT OF VADOSE ZONE & & \\
\hline$>\mathbf{3 0}$ & 1 & & Range & Rating & Weight \\
\hline \multicolumn{3}{|c|}{ NET RECHARGE (millimeter $\cdot$ year $^{-1}$ ) } & Sandy clays & 3 & \\
\hline Range (millimeter year $^{-1}$ ) & Rating & Weight & Metamorphic rock Sandstone, Clay & 4 & \\
\hline $0-50$ & 1 & & Armours and Gravel & 5 & \\
\hline $50-100$ & 3 & 4 & Ferruginous sandstone and coarse sands bitumen & 6 & 5 \\
\hline $100-180$ & 6 & & Clayey Sand & 7 & \\
\hline \multicolumn{3}{|c|}{ AQUIFER MEDIA } & Sand and Gravel & 8 & \\
\hline Range & Rating & Weight & coarse sands & 9 & \\
\hline Sand and Gravel & 8 & & \multicolumn{3}{|c|}{ HYDRAULIC CONDUCTIVITY (meter-day ${ }^{-1}$ ) } \\
\hline Clayey Sands & 4 & ( & Range (meter $\cdot$ day $^{-1}$ ) & Rating & Weight \\
\hline \multirow{2}{*}{\multicolumn{3}{|c|}{ SOIL MEDIA }} & $<4$ & 1 & \multirow{6}{*}{3} \\
\hline & & & $4-12$ & 2 & \\
\hline Range & Rating & Weight & $12-29$ & 4 & \\
\hline Sands ( $10 \%$ to $45 \%$ of Clay) & 7 & & $29-41$ & 6 & \\
\hline Organic matter (peats) & 8 & 2 & $41-82$ & 8 & \\
\hline Sands ( $0 \%$ to $8 \%$ of Clay) & 9 & & $>82$ & 10 & \\
\hline
\end{tabular}

\subsection{Validation Methods of the Vulnerability Map: Sensitivity Analysis Tests}

A sensitivity analysis by two tests was conducted to appreciate the effect of each parameter on the intrinsic sensitivity maps. These tests have been applied in recent studies [16]-[21] to analyze the reliability of vulnerability criteria and validate developed vulnerability maps. They are:

- Map removal sensitivity analysis: This test was developed by [22]. It identifies the sensitivity of the DRASTIC vulnerability map for each of the seven parameters. It is therefore to verify the relevance of the parameters in assessing the intrinsic vulnerability and to deduce the most representative in the application of the method. Thus, the degree of influence of a given parameter on the vulnerability index was evaluated by removal the parameter in overlay process. The comparison of the new vulnerability index with the original index provides a direct measure of the parameter influence. This measure corresponding to the sensitivity index $(S)$ of the parameter is determined from the Equation (2):

$$
S=\left|\frac{V}{N}-\frac{V_{x i}}{n}\right|
$$

With:

$S$ is the sensitivity index of the parameter; 
$V$ is the intrinsic vulnerability index of the method;

$N$ is the total number of parameters used to calculate $V$;

$V_{x i}$ represents the intrinsic vulnerability index obtained after removal of the parameter $X$.

- The single parameter sensitivity analysis: This test was developed by [23]. This test consists to assess the impact of each parameter in calculating the vulnerability index by comparing the calculated weight of the input parameter in each polygon with the theoretical weight assigned by the analytical model [2]. This is an analysis of the real influence of weighting compared to the weights assigned to each parameter. The real or effective weight $(W)$ of a parameter is calculated from Equation (3):

$$
W=\frac{X r+X w}{V} \times 100
$$

With:

$W$ is the effective weight of the parameter;

$X r$ and $X w$ are respectively the rate and the weight assigned to the parameter $X$ and $V$ intrinsic vulnerability index according to the method.

\section{Results and Discussion}

- DRASTIC vulnerability index map

The superposition of the seven punctuated and weighted maps provides DRASTIC index map, which is carried out on the basis of a linear combination between different data values. Each pixel is characterized by a DRASTIC index value. The values of DRASTIC index are defined according to eight classes. These values represent the measurement of the hydrogeological aquifer vulnerability. The vulnerability increases with the index. These values range from 95 to 187 over the entire study area. This value range lies between the extreme values determined by the method that are 23 and 226. To the North and West of the study area, vulnerability index are relatively low and vary from 95 to 131. In the South and East of this zone, the indexes are increasingly important and vary from 131 to 187.

- Groundwater vulnerability map according to DRASTIC method

The application of the DRASTIC method combined to a GIS allowed obtaining the groundwater vulnerability to pollution map of the study area (Figure 3). This map is used to view the main risk areas linked to high index. This map is characterized by four vulnerability classes defined as follows:

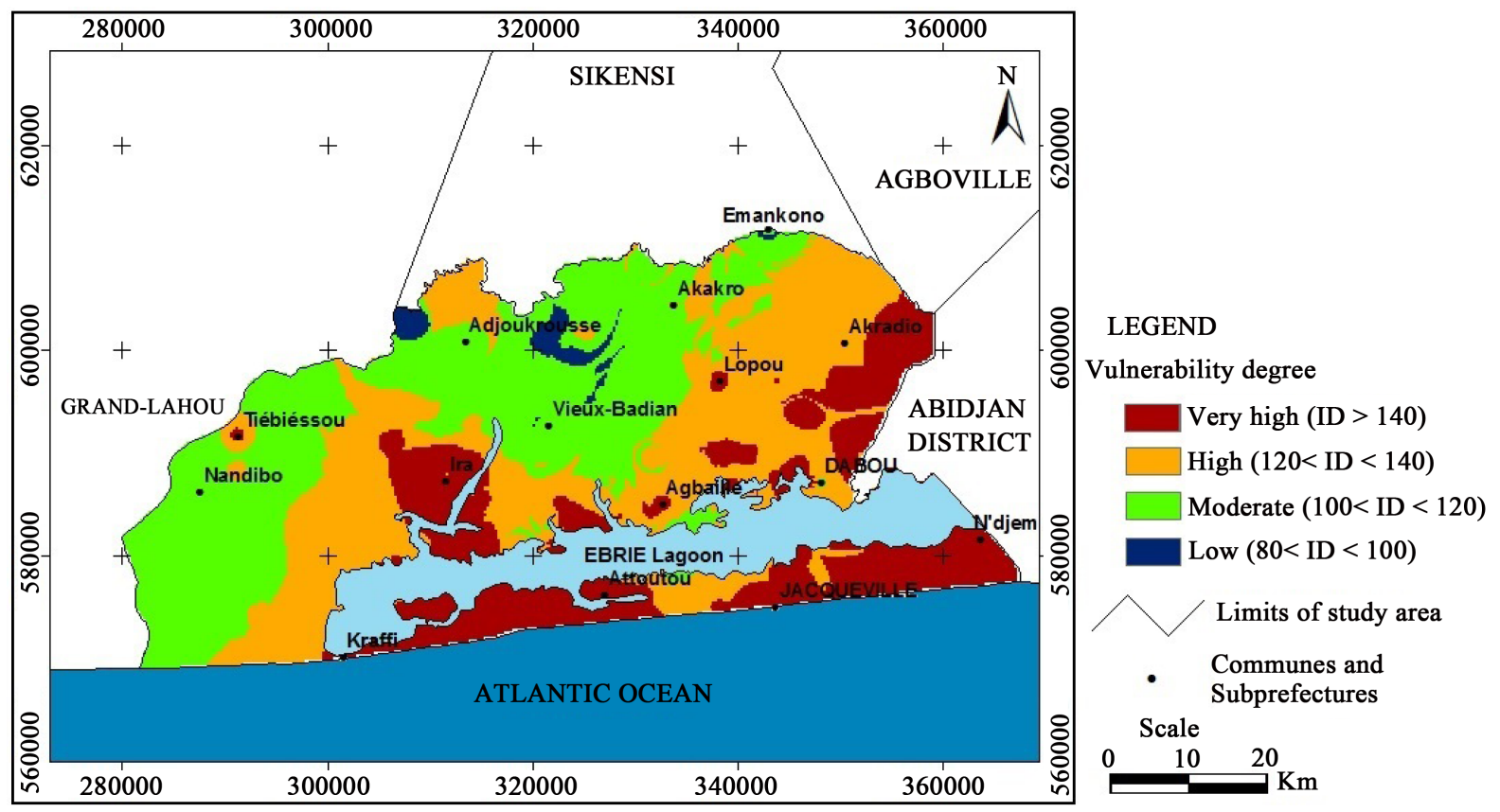

Figure 3. Groundwater vulnerability to pollution map of the study area. 
-ID > 140: very high vulnerability;

$-120<$ ID $<140$ : high vulnerability;

$-100<$ ID < 120: medium or moderate vulnerability;

$-80<$ ID $<100$ : low vulnerability.

The analysis of this map shows a predominance of high and very high vulnerability classes where the index vary from 120 to more than 140 compared to moderate and low vulnerability classes where these index vary from 80 to 120. This map is in raster fashion characterized by a spatial resolution or pixel of $250 \mathrm{~m} \times 250 \mathrm{~m}$ allowing knowing the area bounded by each class depending on the number of pixels given by the GIS.

These results show that: very high vulnerability class occupies $26.22 \%$ of the study area. This class is represented in the South and East of the region where pollution risks incurred by the groundwater is very significant. The entire area contains almost all the department of Jacqueville where Quaternary formations are only represented. This extreme vulnerability can be explained by the depth to water table relatively very weak in the majority of drillings and where the clay fraction likely to attenuate pollution in the sandy formations is weak $(0 \%$ $8 \%)$. The high vulnerability class represents the modal class of the spatial distribution of vulnerability. It occupies $37.71 \%$ of the study area. This class occupies the central part of the study area. The vulnerability is moving towards the North-East and the South-West. The clay content likely to slow down the migration of the pollutant is slightly higher $(10 \%$ to $45 \%)$ in sandy formations as in the previous case. The moderate vulnerability class is represented generally in North and West of the study area. It occupies $34.73 \%$ of the study area. The depth to water table becomes increasingly important with the presence of significant clay content in the formations. Hydraulic conductivity becomes low contrary to the first two classes. All these characteristics confer on the water tables a less significant vulnerability. Low vulnerability class is weakly represented in islands in North with only $1.34 \%$ of the study area. The area occupied by this class is almost negligible compared to those of other classes.

- Results of sensitivity analysis tests of DRASTIC vulnerability map

The maps resulting from the sensitivity analysis test by map removal for each of the seven parameters DRASTIC method are presented in Figures 4-10. These maps show a variation of the spatial distribution of the different classes and index calculated based on the removal of these parameters one. Table 2 summarizes the minimum, average and maximum partial index obtained.

The results in Table 2 indicate that the removal of the topography parameter or the hydraulic conductivity parameter of the overlay process were used to obtain more important average partial index values (respectively 121.48 and 123.53) compared to removal of each other parameters. However, removal the impact of vadose zone parameter of this process has to have the lowest average partial index value (97.50). The partial indexes determined were used to calculate subsequently the sensitivity index for each of the seven DRASTIC parameters (Table 3).

The analysis of the results in Table 3 shows that the depth to water table and the impact of the vadose zone have a strong influence on the vulnerability map with respective sensitivity index of 2.57 and 2.42 . The topography and the hydraulic conductivity seem to have a moderate influence with respective sensitivity index of 1.58 and 1.26. The net Recharge, the aquifer media and the soil media with respective sensitivity index of 0.84 ,

Table 2. Vulnerability partial index calculated by removing each of the seven DRASTIC parameters.

\begin{tabular}{ccccc}
\hline \multirow{2}{*}{$\begin{array}{c}\text { Parameter } \\
\text { Removal }\end{array}$} & \multicolumn{3}{c}{ Index } \\
\cline { 2 - 5 } D & Minimum & Average & Maximum & Standard Deviation (SD) \\
\hline R & 66 & 110.36 & 144 & 10.87 \\
A & 71 & 106.98 & 163 & 14.29 \\
S & 71 & 108.88 & 163 & 16.95 \\
T & $\mathbf{8 1}$ & 115.53 & 173 & 10.07 \\
I & 87 & 121.48 & 177 & 14.22 \\
C & $\mathbf{6 0}$ & 97.50 & 147 & 10.70 \\
\hline
\end{tabular}




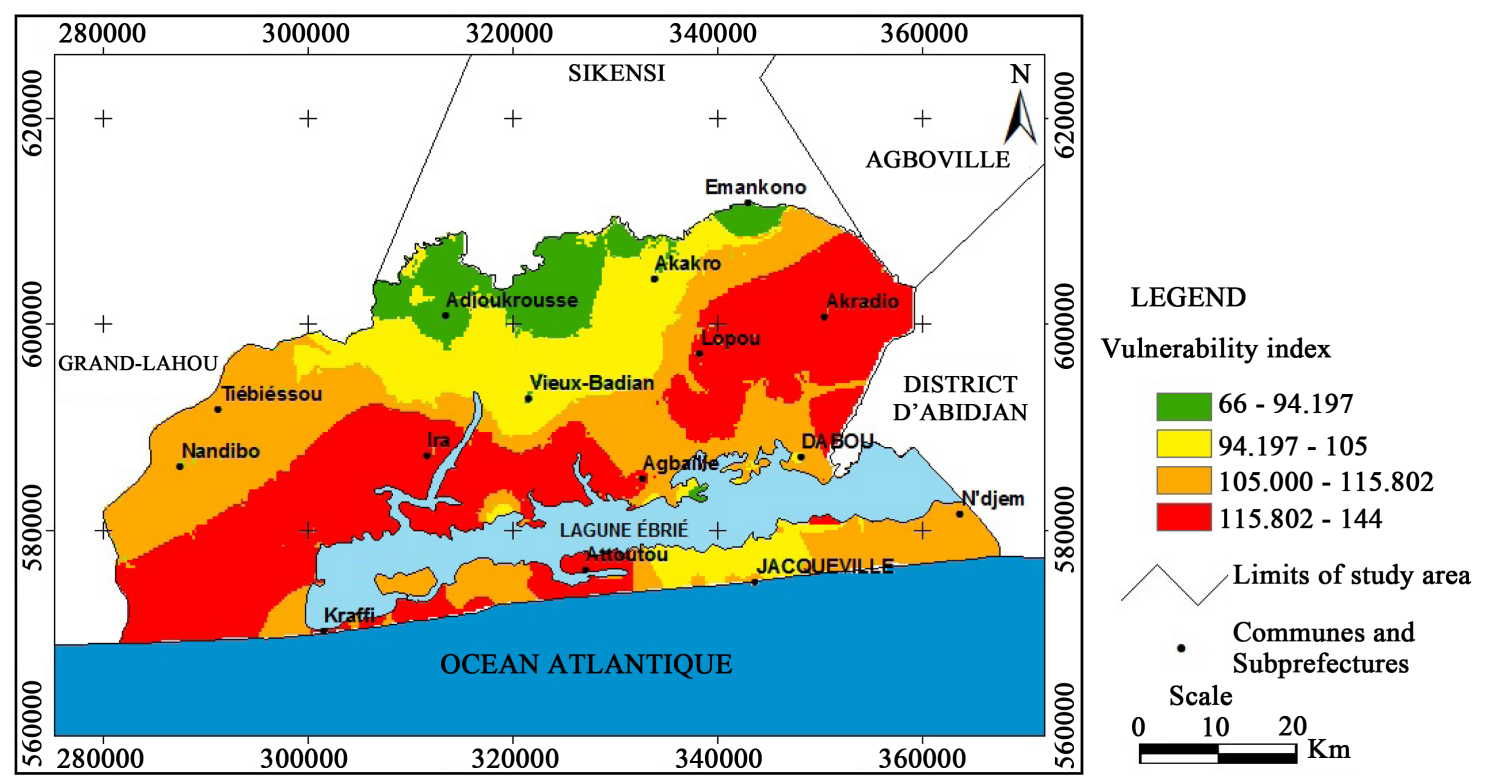

Figure 4. Sensitivity map by removing depth to water.

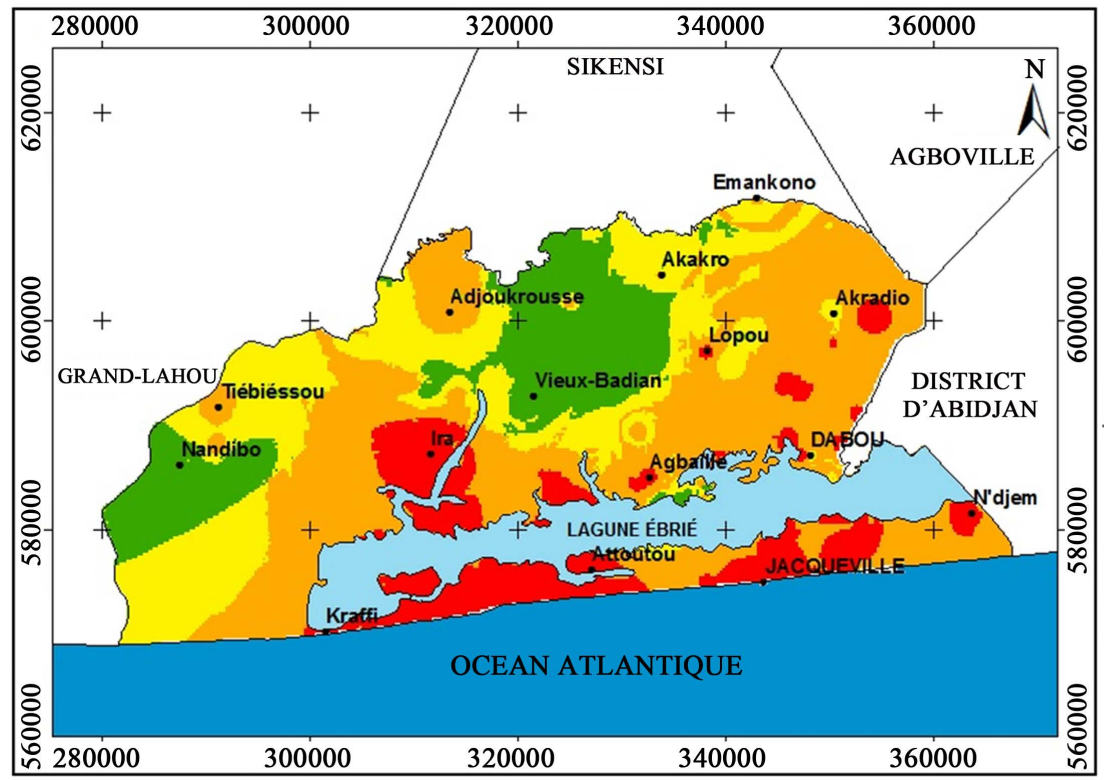

LEGEND

Vulnerability index

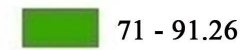

$91.26-101.12$

$101.12-121.39$

$121.39-163$

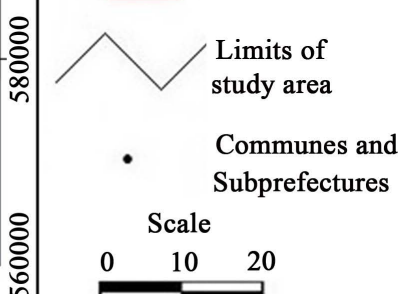

Figure 5. Sensitivity map by removing net recharge.

Table 3. Sensitivity index according to the map removal sensitivity analysis test for DRASTIC vulnerability map.

\begin{tabular}{ccccc}
\hline \multirow{2}{*}{ Parameters } & \multicolumn{3}{c}{ Sensitivity Index } \\
\cline { 2 - 5 } D & S Minimum & S Average & S Maximum & Standard Deviation (SD) \\
R & 0.28 & 2.57 & 2.71 & 0.26 \\
A & 0.45 & 0.84 & 1.74 & 0.30 \\
S & 0.45 & 0.52 & 1.74 & 0.75 \\
T & 0.07 & 0.59 & 2.12 & 0.27 \\
I & 0.93 & 1.58 & 2.79 & 0.30 \\
C & 2.21 & 2.42 & 3.57 & 0.29 \\
\hline
\end{tabular}




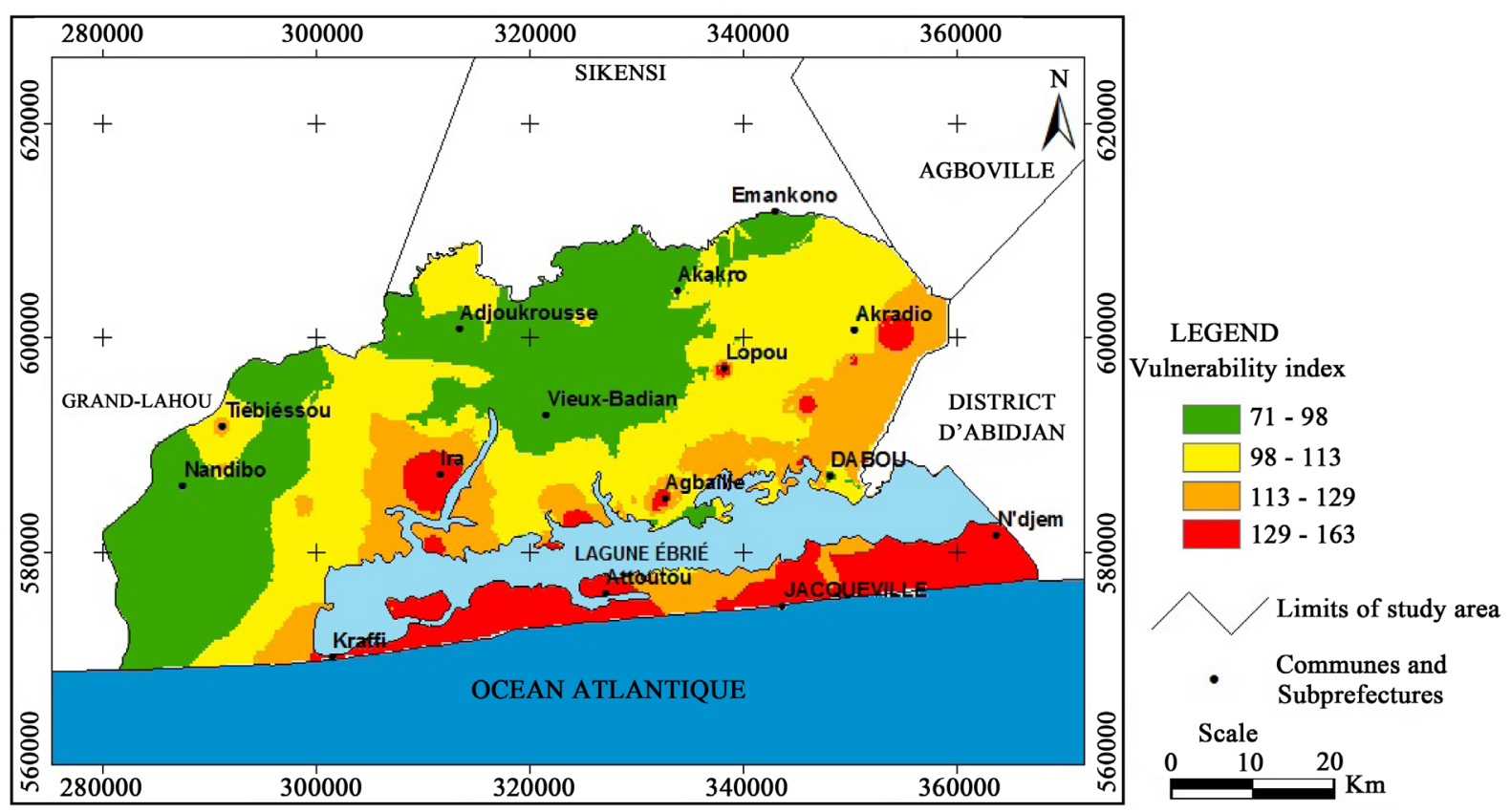

Figure 6. Sensitivity map by removing aquifer media.

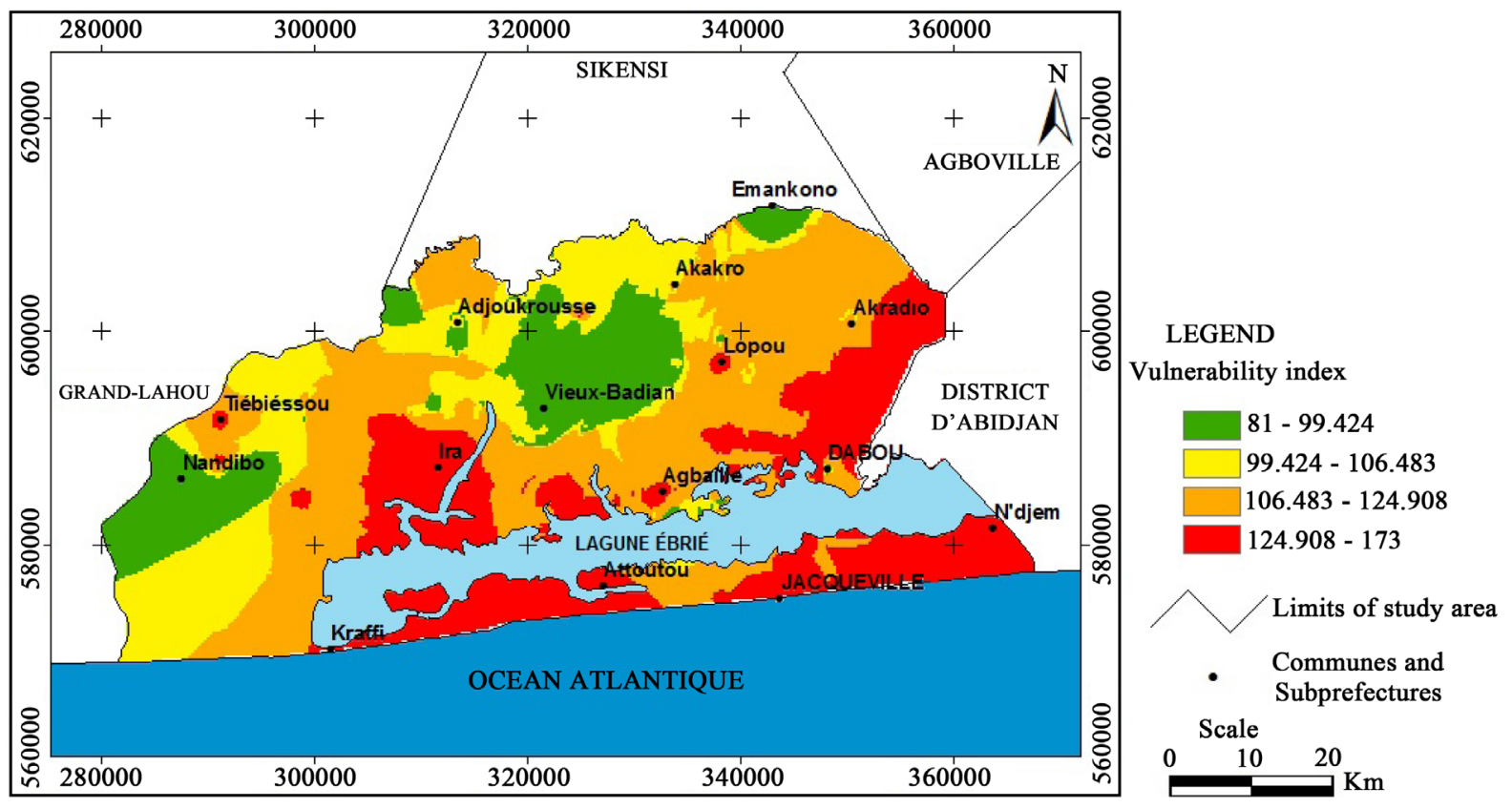

Figure 7. Sensitivity map by removing soil media.

0.52 and 0.59 to a lesser extent affect the DRASTIC vulnerability map index. The aquifer media is the parameter that has recorded the highest value of the standard deviation which indicates an important dispersion or a large variation of the results at the regional scale. Table 4 summarizes the results of the single parameter sensitivity analysis test.

The results in Table 4 show that the parameters such as the aquifer media (13.77\%), the soil media (12.24\%) and the impact of the vadose zone (22.96\%) have their most important effective weight that their theoretical weight (13.04\%, 8.7\% and 21.74\% respectively). For other parameters such as the depth of water table (20.20\%), the net recharge $(15.30 \%)$, the topography $(4.28 \%)$ and the hydraulic conductivity $(11.84 \%)$, the calculated ef- 


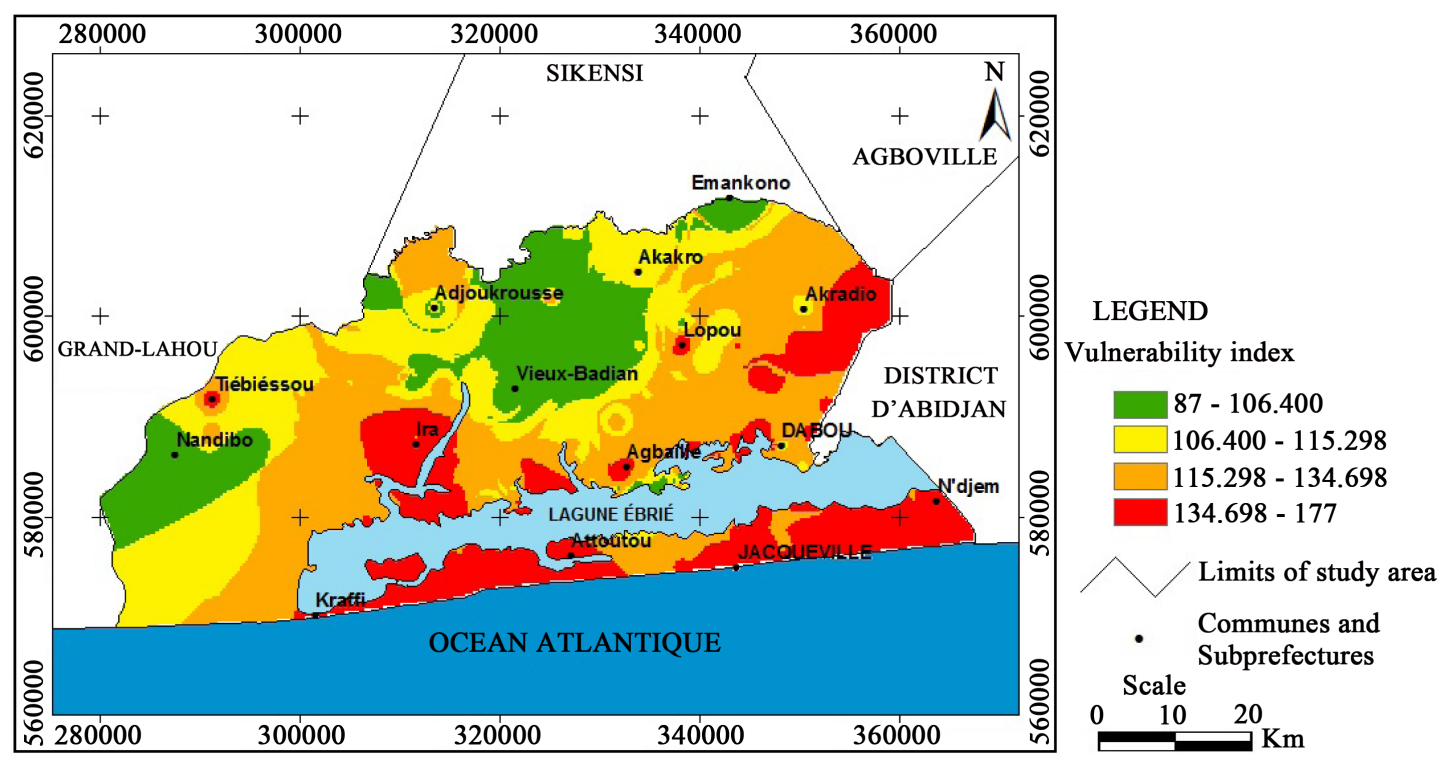

Figure 8. Sensitivity map by removing topography.

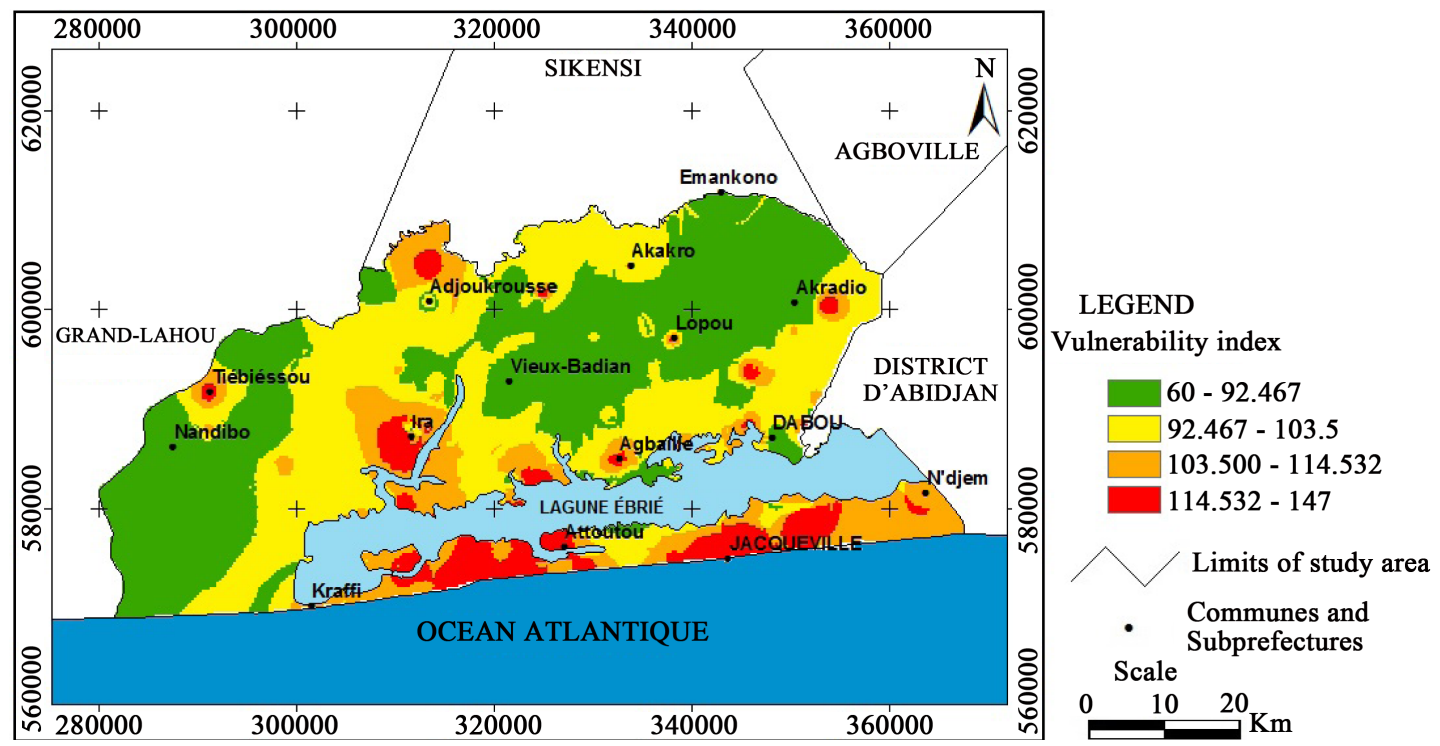

Figure 9. Sensitivity map by removing Impact of vadose zone.

Table 4. Effective weight compared to theoretical weight according to the single parameter sensitivity analysis test for the DRASTIC vulnerability map.

\begin{tabular}{ccccccc}
\hline \multirow{2}{*}{ Parameters } & \multicolumn{5}{c}{ Weight } \\
\cline { 2 - 6 } & Theoretical Weight & Theoretical Weight (\%) & $\mathbf{W}_{\text {min }}$ & $\mathbf{W}_{\text {moy }}$ & W $_{\text {max }}$ \\
\cline { 4 - 7 } D & 5 & 21.74 & 5.26 & 20.20 & 26.74 \\
R & 4 & 17.39 & 4.21 & 15.30 & 12.83 \\
A & 3 & 13.04 & 12.63 & 13.77 & 12.83 \\
S & 2 & 8.7 & 14.74 & 12.24 & 9.63 \\
T & 1 & 4.5 & 1.05 & 4.28 & 5.35 \\
I & 5 & 21.74 & 15.79 & 22.96 & 24.06 \\
C & 3 & 13.04 & 3.16 & 11.84 & 16.04 \\
\hline
\end{tabular}




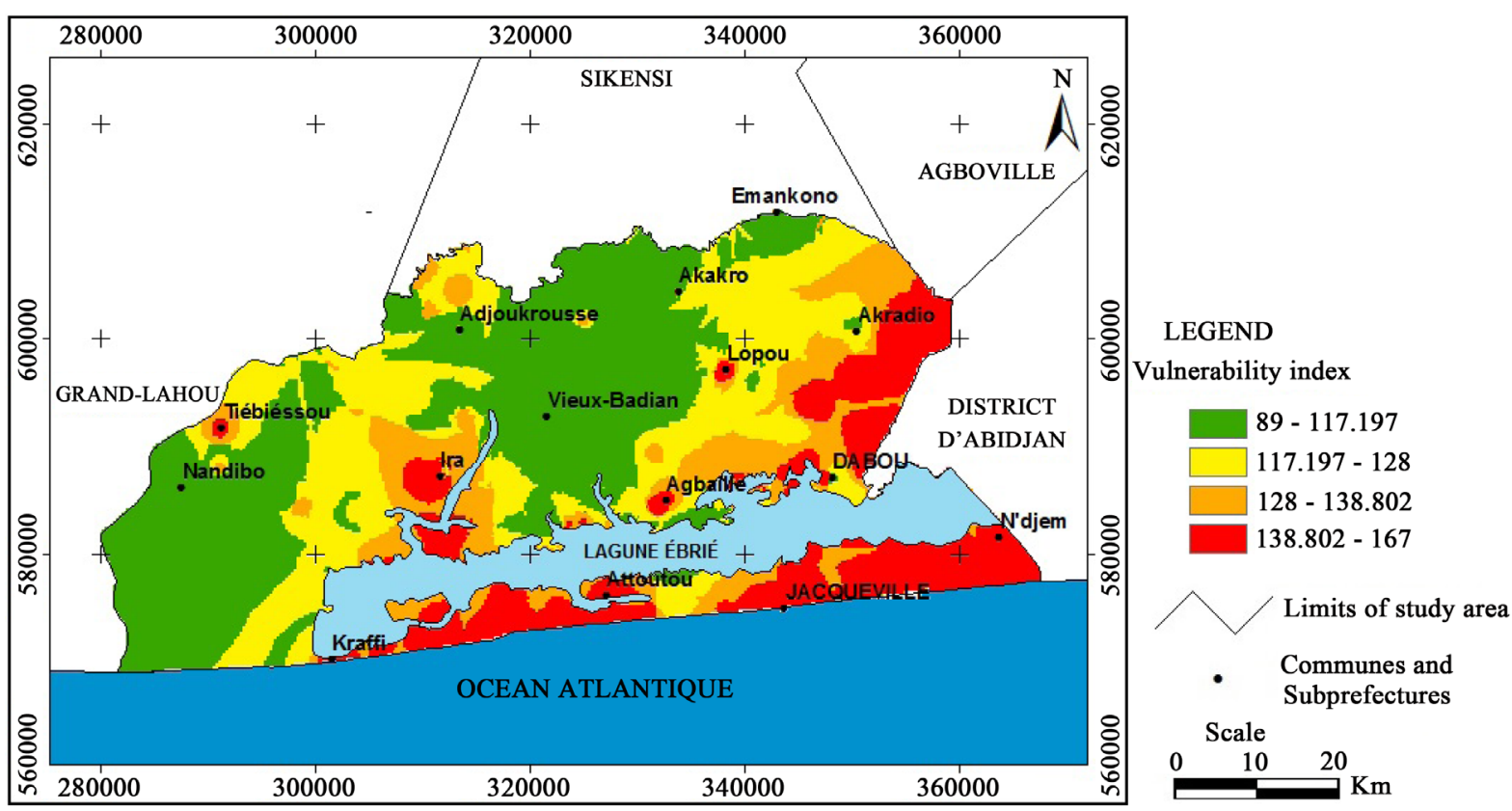

Figure 10. Sensitivity map by removing hydraulic conductivity.

fective weight are lower than the theoretical weight (21.74\%, 17.39\%, 4.35\% and 13.04\% respectively). Indeed, these results demonstrate that modeling in the GIS effectively reduces the subjectivity associated with the allocation of the weights to the various parameters using the DRASTIC method. These weights in fact are readjusted during modeling in the GIS to enable better assessment of the vulnerability.

The DRASTIC vulnerability map of the study area presents four classes: very high, high, moderate and low. This region is characterized by relatively low index compared to those determined by [24] in the Abidjan District (113 - 192) and those obtained by [25] in the Bonoua region (101 to 209) in Côte d'Ivoire. There exists all the same a bringing together of the index values. Indeed, it is in neighboring areas of the Ivorian coastal sedimentary basin that almost have the same hydrogeological characteristics justifying the bringing together of the index values in the assessment of the intrinsic vulnerability. The vulnerability index increases to the East or decreases to the West in this basin. These results show that the ground waters of the study area are less vulnerable than those of the Abidjan District and of the Bonoua region where calculated indexes are higher.

Moreover, it is clear from sensitivity analysis that the depth of water table and impact of the vadose zone have a high sensitivity on the maps of groundwater vulnerability in the study area. When each of these two parameters is removed from the overlay process, this leads to a significant decrease in vulnerability index. These results justify the allocation of greater weight to these two parameters in the application of the DRASTIC method and demonstrate the suitability of coupling GIS and DRASTIC method. These results are similar to those obtained by [20] who have shown that in addition to these parameters, the net recharge and the topography have a strong influence on vulnerability index in the Sub-Prefecture of Songon in the Abidjan District. The studies of [19] revealed that the topography and the depth of the water table are the parameters that have a strong sensitivity to the DRASTIC vulnerability index in the Aboisso District (Côte d'Ivoire) located on the rocky plinth. For [18], it is the impact of the vadose zone and the hydraulic conductivity which significantly influences the groundwater vulnerability map in the Lifen Basin (China). For [16], the aquifer media and the impact of vadose zone have a high sensitivity on vulnerability map of Russeifa area in Jordan. These same results differ from those obtained by [2] who showed that the net recharge, the soil media and the topography are the most influential parameters in assessing the aquifer vulnerability in Kakamigahara (central Japan), and that other parameters have a low to moderate impact. Indeed, the parameters that have a strong sensitivity to the DRASTIC vulnerability maps vary from one study to another. That is why [2] also point out that the variability of these parameters depends on the hydrogeological characteristics of each study area.

That same report is also valid in the comparison the theoretical and actual (or effective) weights to deduce the parameters actually involved and that have a significant impact in the assessment of vulnerability from the point 
of view of weighting. In this study, the parameters such as the soil media, the aquifer media and especially the impact of the vadose zone have been identified as having a significant impact in the vulnerability mapping. These results are in conformity with those of [26] and [20] who have shown that these parameters are, from this point of view, the most deter-mining in the assessing the groundwater vulnerability. [19] also showed that the net recharge made from these parameters while [18] is limited to parameters such as the aquifer media and the soil media. These results come nearer those of [27] and [16] that retained the parameters such as the depth of the water table, the aquifer media or the impact of the vadose zone respectively in the Turbio River valley (Mexico) and in the Russeifa region (Jordan). However, they differ from those of [2] which showed the significant impact of net recharge and hydraulic conductivity in assessing the aquifer vulnerability in Kakamigahara. In this study, the results of the both sensitivity analysis tests show that the impact of the vadose zone is the most important parameter in assessing the vulnerability in the study area. The groundwater vulnerability to pollution is linked to the nature of the sediments (hydrogeological formations) which condition the other parameters essentially the aquifer media and the soil media. According to [21], the impact of the vadose zone reduces the subjectivity in assigning ratings or weight and increases the reliability in assessing of the groundwater vulnerability to pollution. Although, this parameter remains the most important, it requires all other parameters for a more objective assessment of vulnerability. According to [19] the removal of each of the seven parameters involves a sensitivity concerned with this parameter on the vulnerability map. That is why [23] confirmed that the seven DRASTIC parameters have to be considered very important in the assessment of the vulnerability. The DRASTIC vulnerability maps have already been the subject of several criticisms. For [23] these criticisms concern the inevitable subjectivity associated with the selection of seven parameters and assigning ratings and weights used to calculate the vulnerability index. Despite these limitations, the DRASTIC vulnerability map of the study area reflects in our opinion the ground realities. It can therefore be used as tool of decision-making aid for the management or the prevention of groundwater pollution risks. It helps to have an idea on sensitive areas which it will have to take into account during the regional planning [28].

\section{Conclusion}

This study presents the assessment of the groundwater intrinsic vulnerability in the Dabou region from the DRASTIC method which requires seven hydrogeological parameters in its application. The established DRASTIC vulnerability map presents four classes: very high (26.22\%) in the South and the East, high (37.71\%) in the Center, the North-East and North-West, moderate (34.73\%) in the North and West and low $(1.34 \%)$ in the North. The indexes calculated during the establishment of this map vary from 95 to 187 indicating a greater vulnerability. The sensitivity analysis by map removal has shown that the impact of the vadose zone and the depth to water table has a much larger influence on the assessment of the groundwater intrinsic vulnerability in the study area. The vulnerability of groundwater in this region is strongly linked to these two parameters that allow for higher index therefore know the most sensitive areas. The single parameter sensitivity analysis shows that the aquifer media and the soil media have a more significant impact that the net recharge, the topography and the hydraulic conductivity in terms of weighting. The GIS used in this study by allowing the application of the DRASTIC method provide certain objectivity in the assessment of vulnerability. It allows easily per- forming the sensitivity analysis of groundwater vulnerability map of the Dabou region. This map is now a powerful tool of assistance in the prevention of the groundwater pollution risks. The vulnerability map constitutes a tool for monitoring human activities in the regional planning for the sustainable conservation the groundwater quality.

\section{Acknowledgements}

I would like to thank my supervisor Professor Jean Patrice JOURDA of Félix Houphouët-Boigny University (Côte d'Ivoire) for his support and guidance in completing this project. I would also like to thank Professor Jean Kan KOUAMÉ and Dr. Kouakou Serge DEH for their important contribution and all the members of the Laboratory of Remote Sensing and Spatial Analysis Applied to Hydrogeology for the success of this project.

\section{References}

[1] Morris, B.L., Lawrence, A.R., Chilton, P.J.C., Adams, B., Calow, R.C. and Klinck, B.A. (2003) Groundwater and Its Susceptibility to Degradation: A Global Assessment of the Problem and Options for Management. Early Warning and 
Assessment Report Series, RS. 03-3, United Nations Environmental Program, Nairobi, Kenya, 126. http://www.unep.org/DEWA/water/groundwater/pdfs/Groundwater_INC_cover.pdf

[2] Babiker, I.S., Mohamed, M.A.A., Hiyanna, T. and Kato, A. (2005) A GIS Based DRASTIC Model for Assessing Aquifer Vulnerability in Kakamigahara Heights, Gifu Prefecture, Central Japan. Science of the Total Environment, 345, 127-140. http://dx.doi.org/10.1016/j.scitotenv.2004.11.005

[3] Dridi, L. and Schäfer, G.L. (2006) Vapor Flux of the Chlorinated Solvents Quantization from a Source Porous Aquifer to the Atmosphere: Bias Relative to the Non-Uniformity of the Water Content and the Non-Stationary of the Transfer. Mechanical Report, 334, 611-620.

[4] Melloul, A. and Collin, M. (1994) Water Quality Factor Identification by the "Principal Components" Statistical Method. Water Science Technology, 34, 41-50.

[5] Foster, S.S.D. (1987) Fundamental Concepts in Aquifer Vulnerability, Pollution Risk and Protection Strategy. Hydrological Resources Processes and Informations, 38, 69-86.

[6] Tapsoba, S.A. (1995) Contribution to the Geological and Hydrogeological Study of Dabou Region (Southern of Côte d'Ivoire): Hydrochemistry, Isotopic and Cationic Aging Index of Groundwater. PhD Thesis, 3rd Cycle National University of Côte d'Ivoire, 200.

[7] Statistic National Institute (SNI) (2010) General Census of Population and Housing. http://fr.wikipedia.org/wiki/Dabou http://fr.wikipedia.org/wiki/Jacqueville_.

[8] Tastet, J.P. (1979) Quaternary Sedimentary and Structural Environments of the Coastline of the Guinea Gulf (Côte d'Ivoire, Togo, Benin). PhD Thesis, (State) of Science University of Bordeaux 1, 181.

[9] Jourda, J.P. (1987) Contribution to the Geological and Hydrogeological Study of the Area of Greater Abidjan (Côte d'Ivoire). PhD Thesis, 3rd Cycle Scientific, Technical and Medical University of Grenoble, France, 319.

[10] Aghui, N. and Biémi, J. (1984) Geology and Hydrogeology of Groundwater in the Region of Abidjan and Contamination Risks. Annals of the National University of Côte d'Ivoire Series C, 20, 331-347.

[11] Aller, L., Bennett, T., Lehr, J., Petty, R.J. and Hackett, G. (1987) DRASTIC: A Standardized Method for Evaluating Potential Ground Water Pollution Using Hydrogeological Settings. EPA/600/2-87-035, 622 p.

[12] Schnebelen, N., Platel, J.P., Lenindre, Y. and Baudry, D. (2002) Groundwater Management in Aquitaine Year 5. Segment Operation, Protection of the Water Table of the Oligocene in the Bordeaux Region. Report BRGM/RP-51178-FR, $20 \mathrm{p}$.

[13] Mohamed, R.M. (2001) Evaluation and Mapping of Alluvial Aquifer Vulnerability to Pollution of the Plain of El Madher, Algerian North-East, Using the DRASTIC Method. Science and Planetary Change/Drought, 12, 95-101.

[14] European Network for Research on Global Change (ENRICH) (2001) Climate-West Africa; A Network for: Harmonization of Climate Prediction for Mitigation of Global Change Impacts in Sudano-Sahelian. Energy, Environment and Sustainable Development Program Key Action 2. Global Change Climate and Biodiversity, University of East Anglia, Norwich.

[15] Smida, H., Abdellaoui, C., Zairi, M. and Dhia, B.H. (2010) Mapping of Agricultural Areas Vulnerable to Pollution by the DRASTIC Method Coupled with a Geographic Information System (GIS): Case the Chaffar Water Table (South of Sfax, Tunisia). Science and Planetary Change/Drought, 21, 131-146.

[16] El-Naqa, A., Hammouri, N. and Kuisi, M. (2006) GIS-Based Evaluation of Groundwater Vulnerability in the Russeifa Area, Jordan. Revisita Mexicana de Ciencias Geológicas, 23, 277-287.

[17] Akbari, G.H. and Rahimi-Shahrbabaki, M. (2011) Sensitivity Analysis of Water at Higher Risk Subjected to Soil Contamination. Computer Methods in Civil Engineering, 2, 83-94.

[18] Samake, M.H., Tang, Z., Hlaing, W., Ndoh, M.I., Kasereka, K. and Balogun, W. (2011) Groundwater Vulnerability Assessment in Shallow Aquifer in Linfen Basin, Shanxi Province, China Using DRASTIC Model. Journal of Sustainable Development, 4, 53-71. http://dx.doi.org/10.5539/jsd.v4n1p53

[19] Doumouya, I., Dibi, B., Kouame, I.K., Saley, B., Jourda, J.P., Savane, I. and Biémi, J. (2012) Modeling of Favorable Zones for the Establishment of Water Points by Geographical Information System (GIS) and Multicriteria Analysis (MCA) in the Aboisso Area (South-East of Côte d'Ivoire). Environmental Earth Science, 67, 1763-1780. http://dx.doi.org/10.1007/s12665-012-1622-2

[20] Dibi, B., Kouame, K.I., Konan-Waidhet, A.B., Savane, I., Biémi, J., Nedeff, V. and Lazar, G. (2012) Impact of Agriculture on the Quality of Groundwater Resources in Peri-Urban Zone of Songon (Côte d'Ivoire). Environmental Engineering and Management Journal, 11, 2173-2182.

http://www.academia.edu/18674209/Impact_of_agriculture_on_the_quality_of_groundwater_resources_in_peri-urban zone_of_Songon_Cote_D_ivoire_

[21] Kouamé, K.I., Douagui, G.A., Koffi, K., Dibi, B. and Kouassi, K.K. (2013) Modeling of Quaternary Groundwater 
Pollution Risk by GIS and Multicriteria Analysis in the Southern District Share of Abidjan (Ivory Coast). Journal of Environmental Protection, 4, 1213-1223. http://dx.doi.org/10.4236/jep.2013.411139

[22] Lodwick, W.A., Monson, W. and Svoboda, L. (1990) Attribute Error and Sensitivity Analysis of Map Operations in Geographical Information Systems: Suitability Analysis. International Journal of Geographical Information Systems, 4, 413-428. http://dx.doi.org/10.1080/02693799008941556

[23] Napolitano, P. and Fabbri, A.G. (1996) Single Parameter Sensitivity Analysis for Aquifer Vulnerability Assessment Using DRASTIC and SINTACS. In: Kovar, K. and Nachtnebel, H.P., Eds., HydrolGis Application of Geographic Information Systems in Hydrology and Water Resources Management, IAHS Publication, Wallingford, 559-566.

[24] Kouamé, K.J. (2007) Contribution to the Integrated Water Resources Management (IWRM) of the Abidjan District (South Côte d'Ivoire): Tools for Decision for the Prevention and Protection of Groundwater against Pollution. PhD Thesis, University of Cocody, Abidjan, 226 p.

[25] Aké, G.E. (2009) Impacts of Climate Variability and Anthropogenic Pressures on Water Resources of Bonoua Region (South-East of Côte d'Ivoire). PhD Thesis, University of Cocody, Abidjan, $201 \mathrm{p}$.

[26] Al-Hanbali, A. and Kondoh, A. (2008) Groundwater Vulnerability Assessment and Evaluation of Human Activity Impact (HAI) within the Dead Sea Groundwater Basin, Jordan. Hydrogeology Journal, 16, 499-510. http://dx.doi.org/10.1007/s10040-008-0280-7

[27] Ramos, L.J.A. and Castillo, R.R. (2003) Aquifer Vulnerability Mapping in the Turbio River Valley, Mexico: A Validation Study. Geofísica Internacional, 42, 141-156.

[28] Jourda, J.P. (2005) Application Methodology Remote Sensing Techniques and Geographical Information Systems to the Study of Fissured Aquifers of West Africa. Hydrotechnic Concept of Space: The Case of Côte d'Ivoire Testing Areas. PhD Thesis, University of Cocody, Abidjan, 430 p. 